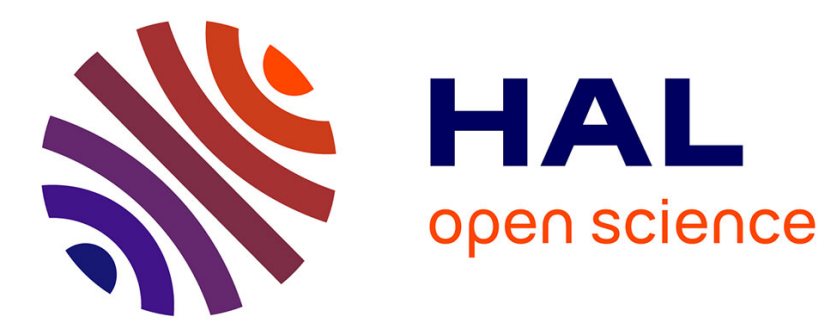

\title{
The Gigatracker, the silicon beam tracker for the NA62 experiment at CERN
}

L. Federici, G. Aglieri Rinella, D. Alvarez Feito, R. Arcidiacono, C. Biino, S. Bonacini, A. Ceccucci, S. Chiozzi, E. Cortina Gil, A. Cotta Ramusino, et al.

\section{- To cite this version:}

L. Federici, G. Aglieri Rinella, D. Alvarez Feito, R. Arcidiacono, C. Biino, et al.. The Gigatracker, the silicon beam tracker for the NA62 experiment at CERN. 15th Vienna Conference on Instrumentation, Feb 2019, Vienna, Austria. pp.162127, 10.1016/j.nima.2019.04.081 . hal-02507900

\section{HAL Id: hal-02507900 \\ https://hal.science/hal-02507900}

Submitted on 9 Apr 2020

HAL is a multi-disciplinary open access archive for the deposit and dissemination of scientific research documents, whether they are published or not. The documents may come from teaching and research institutions in France or abroad, or from public or private research centers.
L'archive ouverte pluridisciplinaire $\mathbf{H A L}$, est destinée au dépôt et à la diffusion de documents scientifiques de niveau recherche, publiés ou non, émanant des établissements d'enseignement et de recherche français ou étrangers, des laboratoires publics ou privés. 


\title{
The GigaTracKer, the silicon beam tracker for the NA62 experiment at CERN
}

\author{
Luca Federici \\ On behalf of the NA62 GigaTracKer group
}

Federici, L ; Rinella, GA ; Feito, DA ; Arcidiacono, R ; Biino, C ; Bonacini, S ; Ceccucci, A ; Chiozzi, S ; Gil, EC ; Ramusino, AC ; Degrange, J ; Fiorini, M ;

Gamberini, E ; Gianoli, A ; Kaplon, J ; Kleimenova, A ; Kluge, A ; Mapelli, A ; Marchetto, F ; Migliore, E ; Minucci, E. ; Morel, M ; Noel, J ; Noy, M ;

Perktold, L ; Perrin-Terrin, M ; Petagna, P ; Petrucci, F ; Poltorak, K ; Romagnoli, G ; Ruggiero, G ;Velghe, B ; Wahl, H . 
The GigaTracKer, the silicon beam tracker for the NA62 experiment at CERN

\author{
Luca Federici \\ On behalf of the NA62 GigaTracKer group
}




\section{Outline}

- Introduction;

- Specifications;

- GTK description;

- GTK performances;

- NA62 data;

- Conclusions.

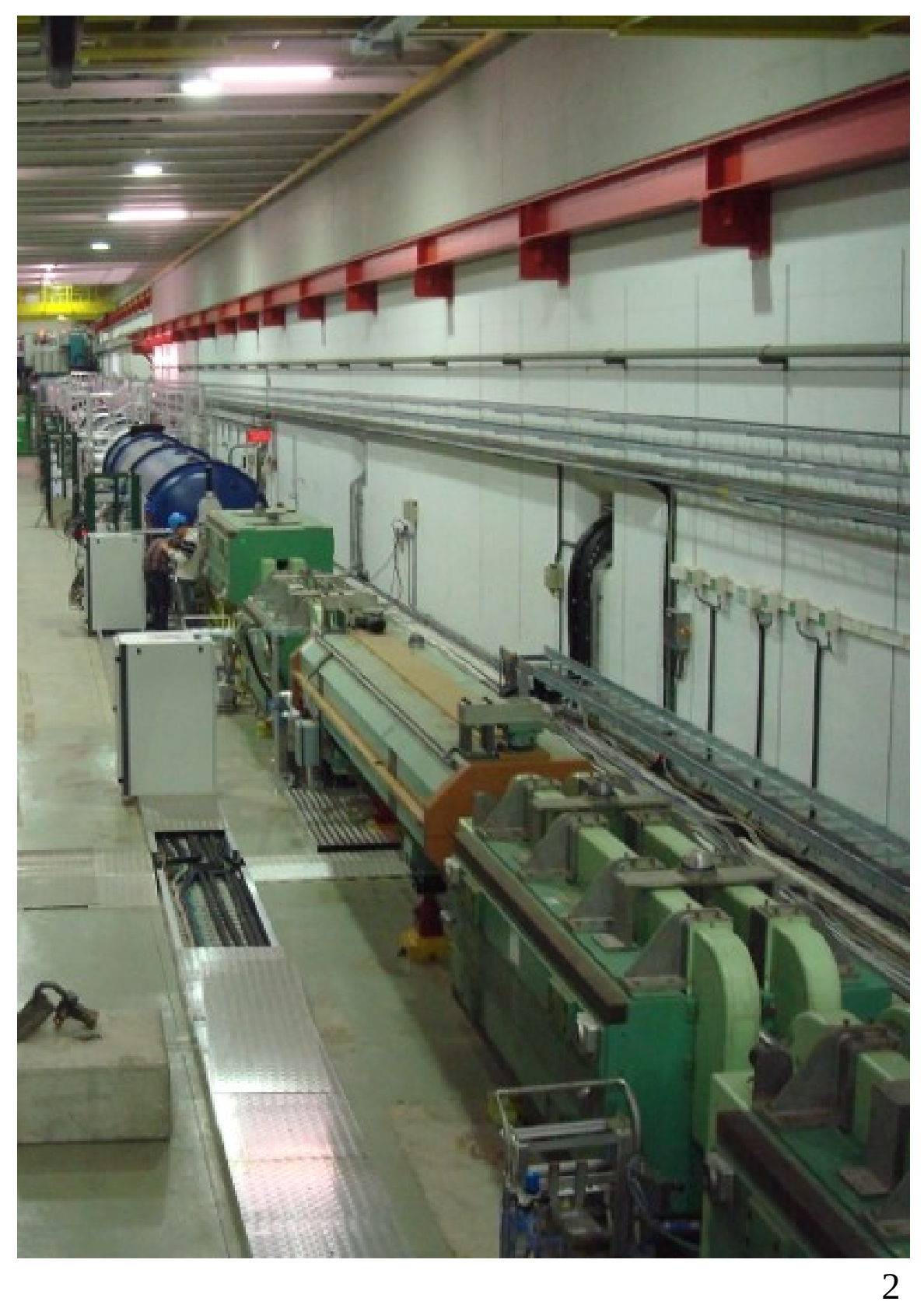




\section{Introduction - The NA62 experiment}

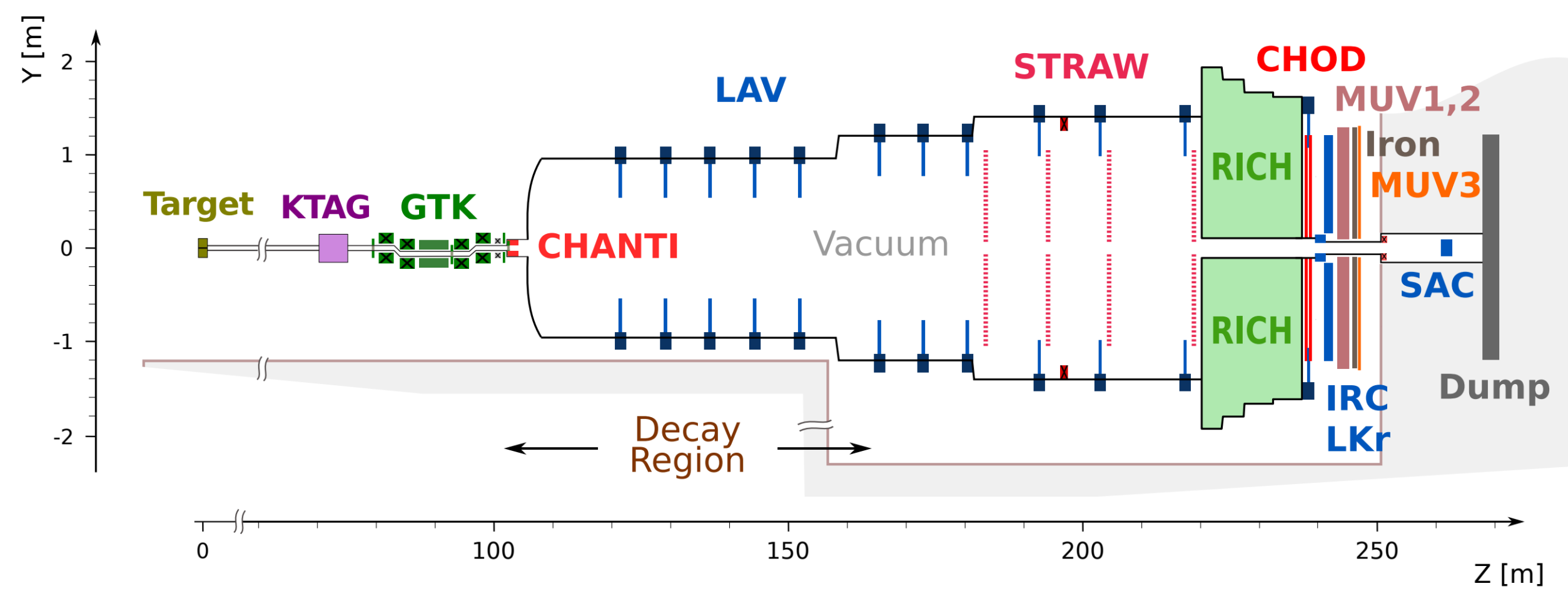

$\mathrm{B}_{\mathrm{SM}}\left(\mathrm{K}^{+} \rightarrow \pi^{+} v \bar{v}\right)=(8.4 \pm 1) \times 10^{-11} \quad$ Standard Model prediction

Goal $\rightarrow 10 \%$ precision in few years of data taking

$p_{2 n d}=75 \mathrm{GeV} @ 750 \mathrm{MHz} \quad \pi^{+}(70 \%), p(23 \%), \mathrm{K}^{+}(6 \%)$ 


\section{Specifications}

High precision measurement of:

- Direction (GTK1+ GTK3)

- Momentum (GTK1+GTK3+GTK2)

- And particle arrival time

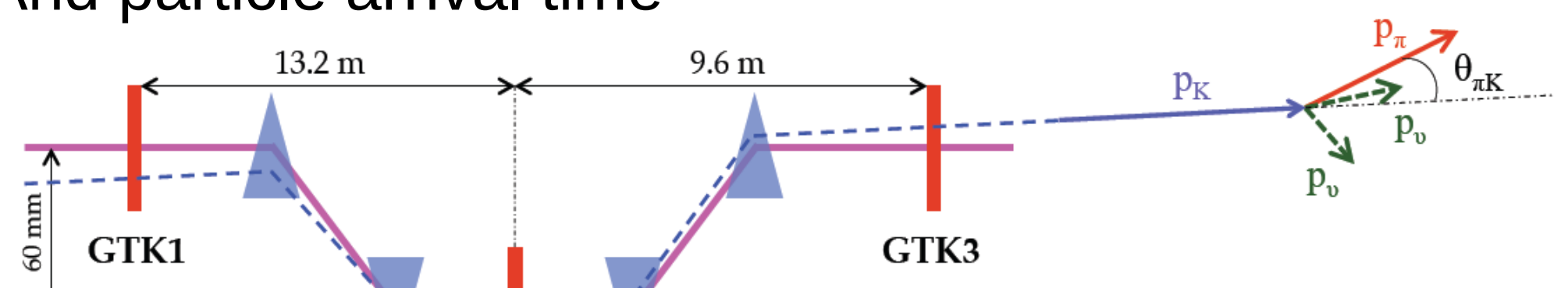

Direction and momentum used to reconstruct the missing mass

$\theta_{x, y}=p_{x, y} / p_{z}=16 \mu \mathrm{rad}$

$\delta p / p=0.2 \%$

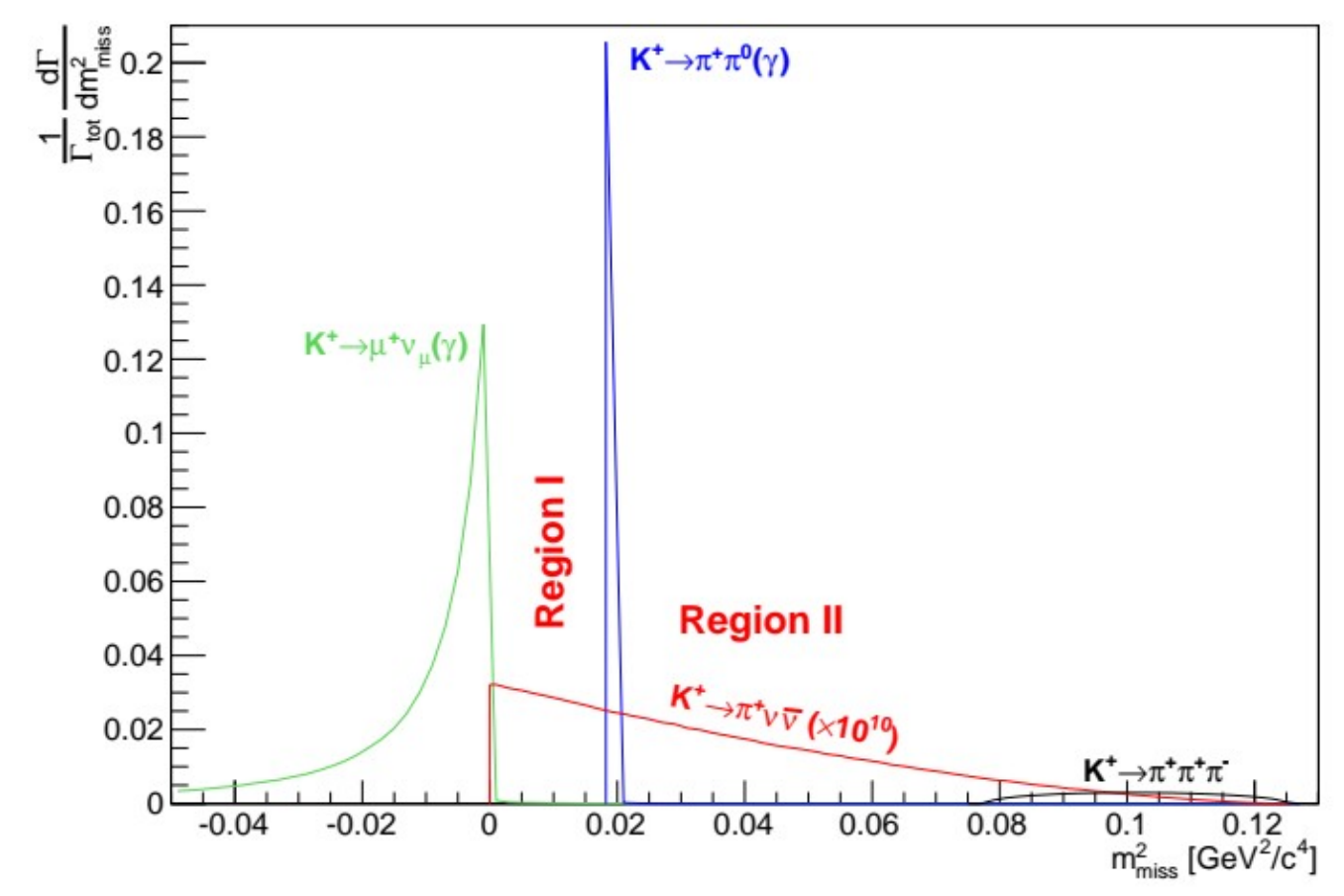




\section{Specifications}

Min. inelastic scattering $\rightarrow$ max material budget $=0.5 \% \mathrm{X}_{0} /$ station

Particle tracks reconstruction $\rightarrow$ Pixel time-stamp resolution $<200 p s$

particle fluence at nominal intensity during 100 days:

$$
2 \times 10^{14} 1 \mathrm{MeV} \mathrm{n}_{\mathrm{eq}} / \mathrm{cm}^{2}
$$

Design of compact, standard modules to be rapidly replaced (within half a day) before significant performance degradation 


\section{the sensor}

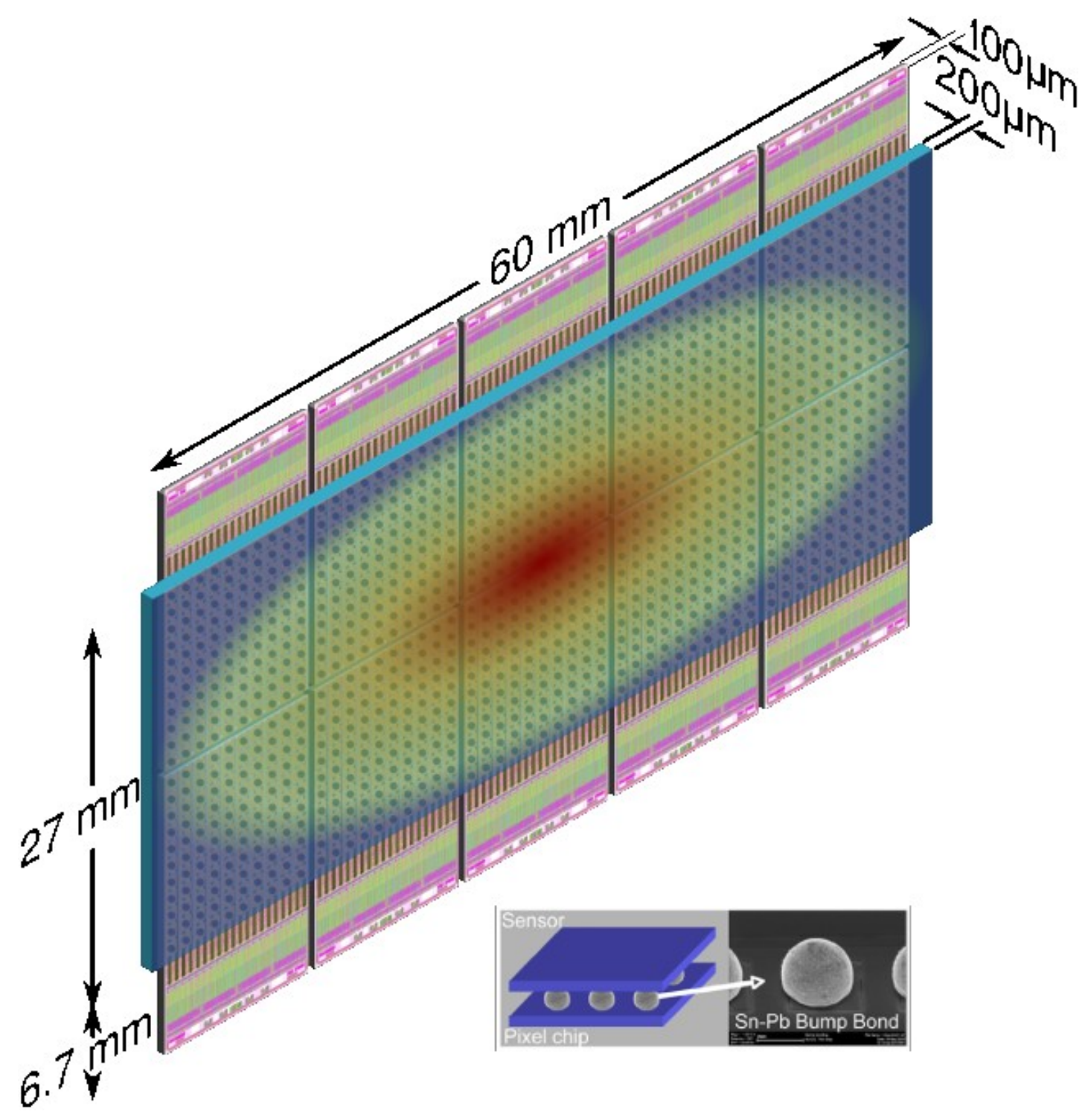

Sensitive region of $27 \times 60 \mathrm{~mm}^{2}$

n-in-p type

$200 \mu \mathrm{m}$ thick $\left(0.2 \% \mathrm{X}_{0}\right)$

Bump bonded to $10 \mathrm{ROC}$ 


\section{the TDCPix}

- 130nm technology.

- $100 \mu \mathrm{m}$ thick $\left(0.1 \% \mathrm{X}_{0}\right)$

- Pixel size 300 x $300 \mu m^{2}$

- 1800 pixels

- amp. peak time $=5 \mathrm{~ns}$

- TDC bin size $=98 p s$

- SEU mitigation

- hit time-stamp and pixel address encoded into a 48bits word

- 4x3.2 GHz serializers

Power dissipation 4.1W

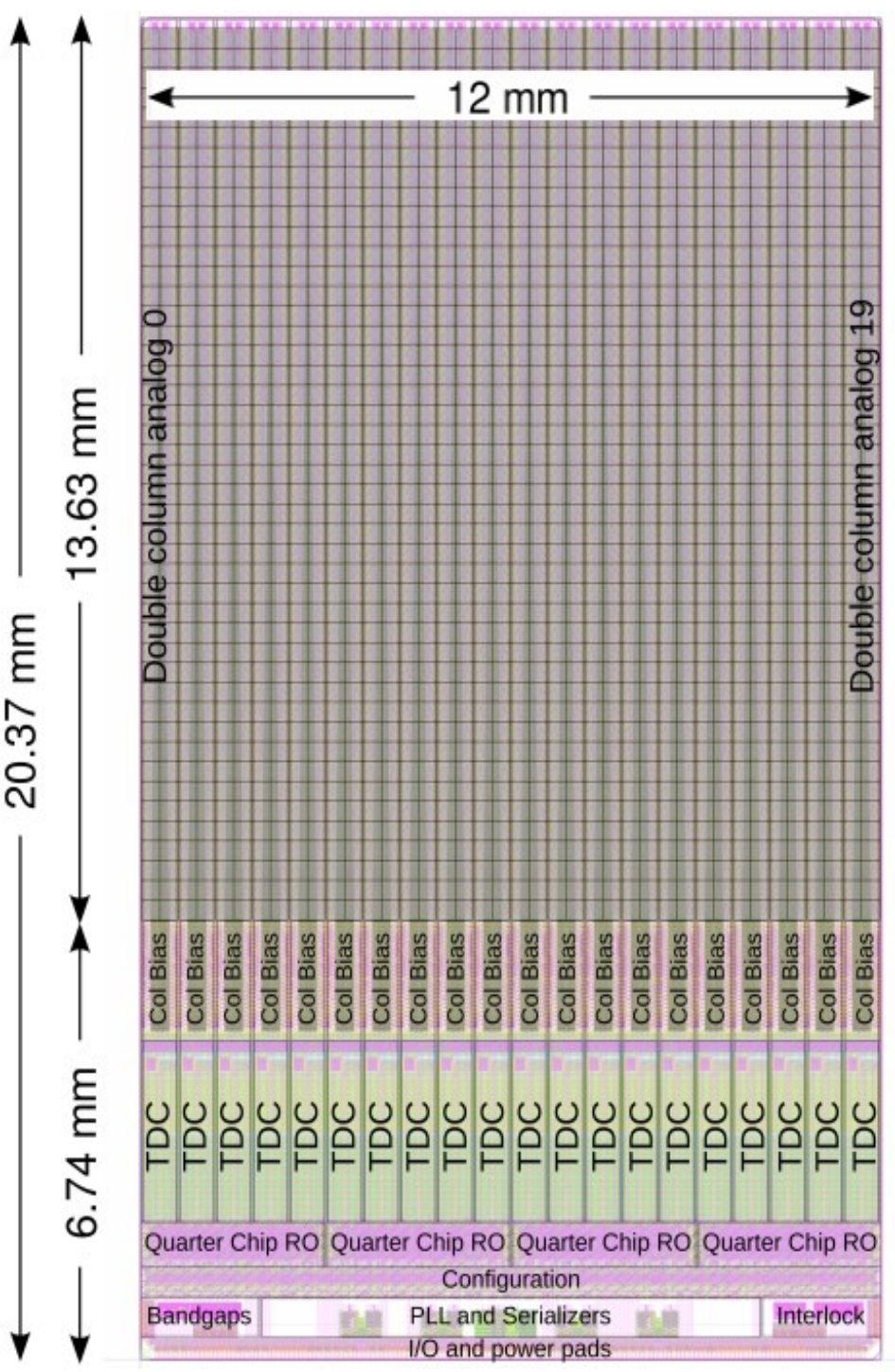

$40 \times 45$

Pixel matrix

Hit digitization

\section{EOC}

Timestamp

serialization 


\section{the micro-channels cooling plate}

Detector in vacuum $\left(-10^{-7} \mathrm{mbar}\right)$

- micro-channels technology

$-210 \mu \mathrm{m}$ thick $\left(0.2 \% \mathrm{X}_{0}\right)$

- $70 \times 80 \mathrm{~mm}^{2}$

- liquid coolant $\mathrm{C}_{6} \mathrm{~F}_{14}$

- front-end electronics and sensor at $-10^{\circ} \mathrm{C}$
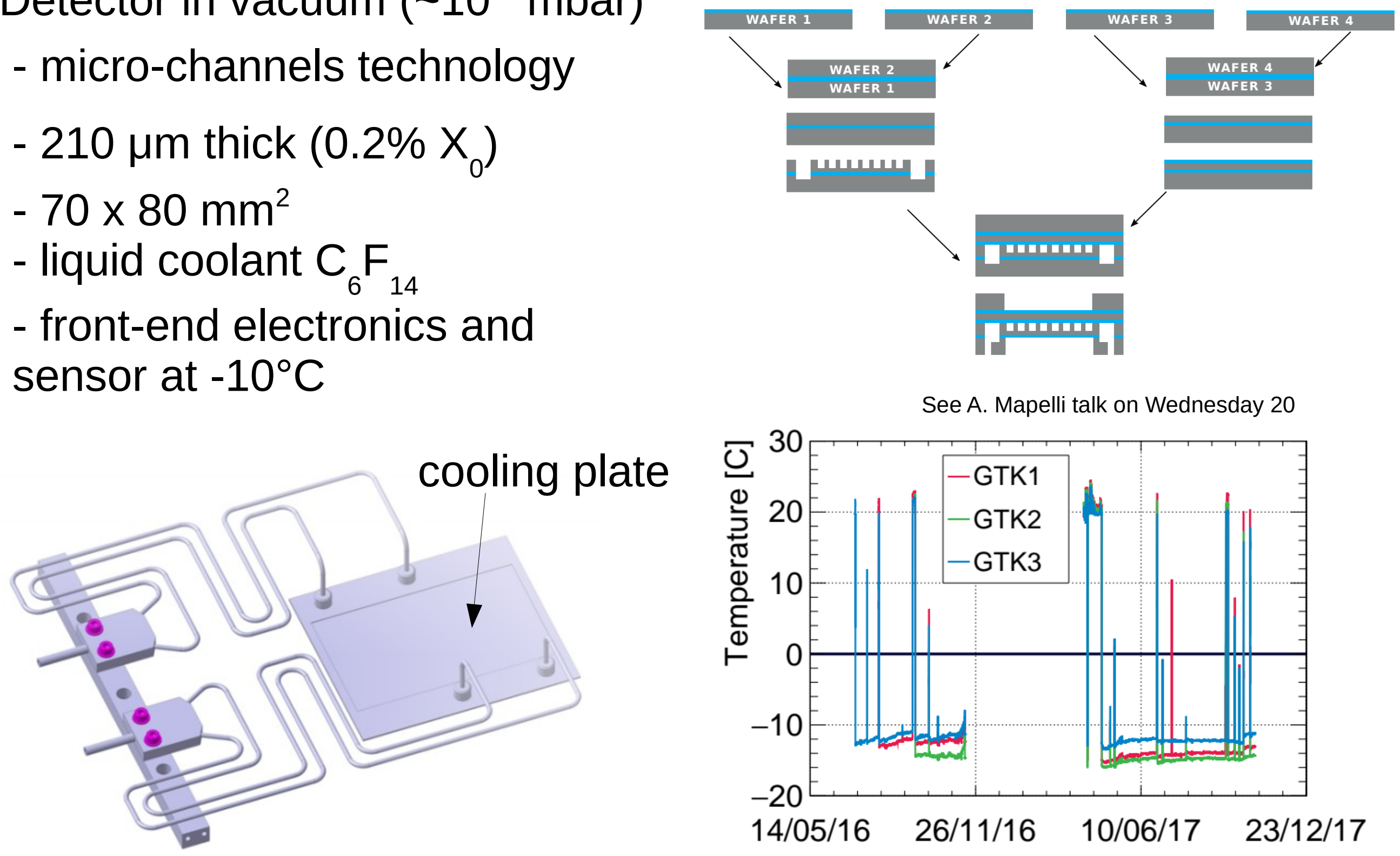

See A. Mapelli talk on Wednesday 20

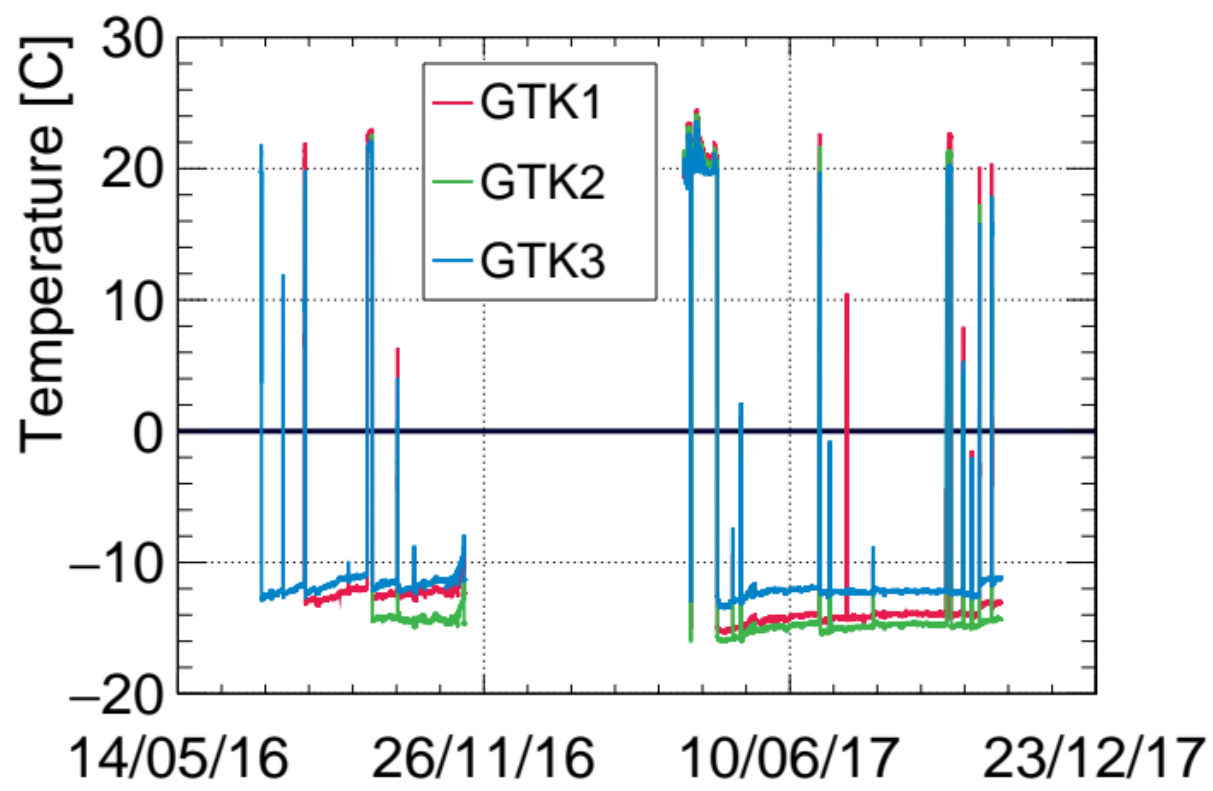




\section{The carrier board}

- chips sensor and cooling plate assembly hosted in the countersink of the carrier board

- 14 layer T-shaped PCB

- sealed in an aluminum frame

- 1450 bonding pads spaced by $73 \mu \mathrm{m}$

- opto-electrical devices
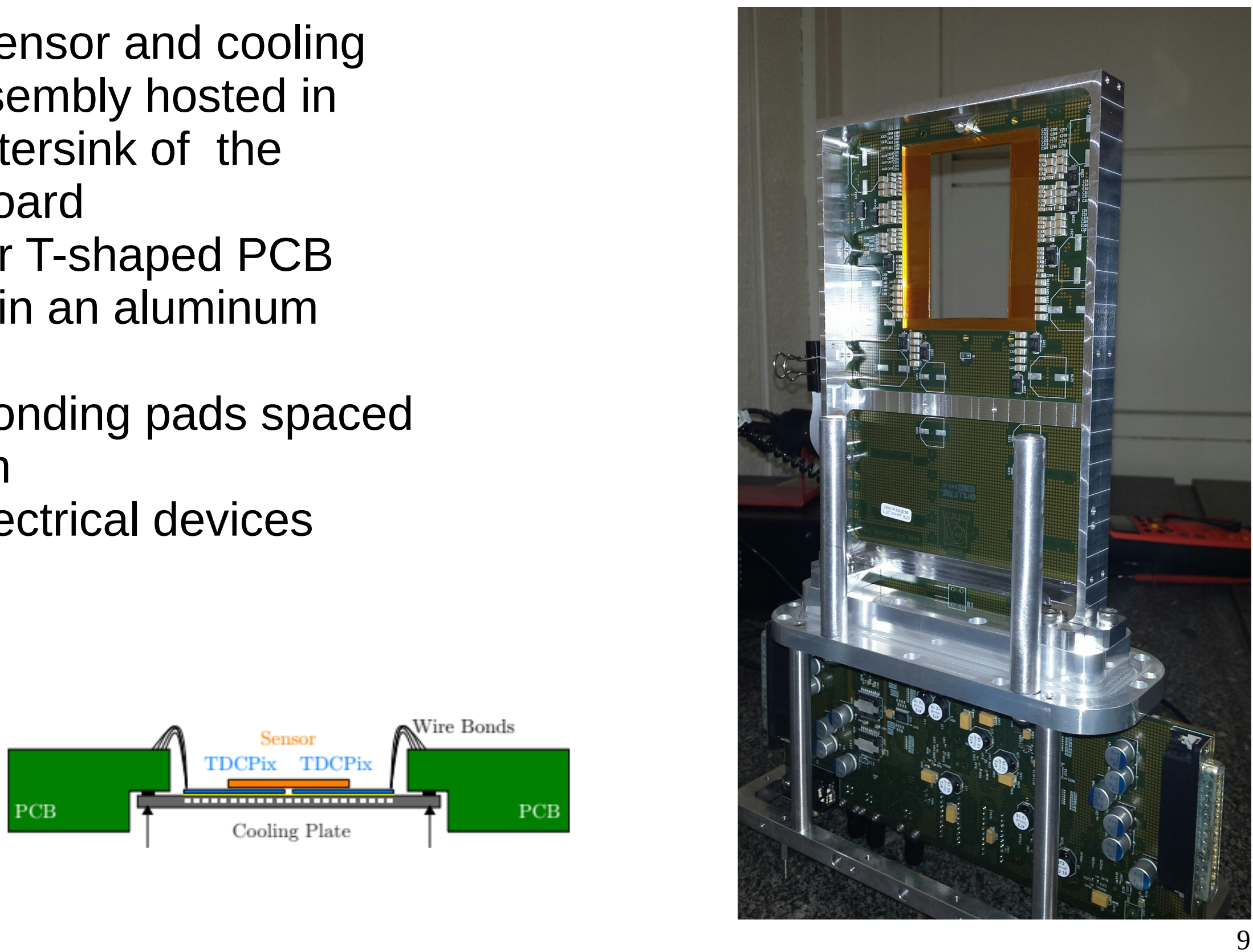


\section{The GigaTraKer Module}

Sensor side

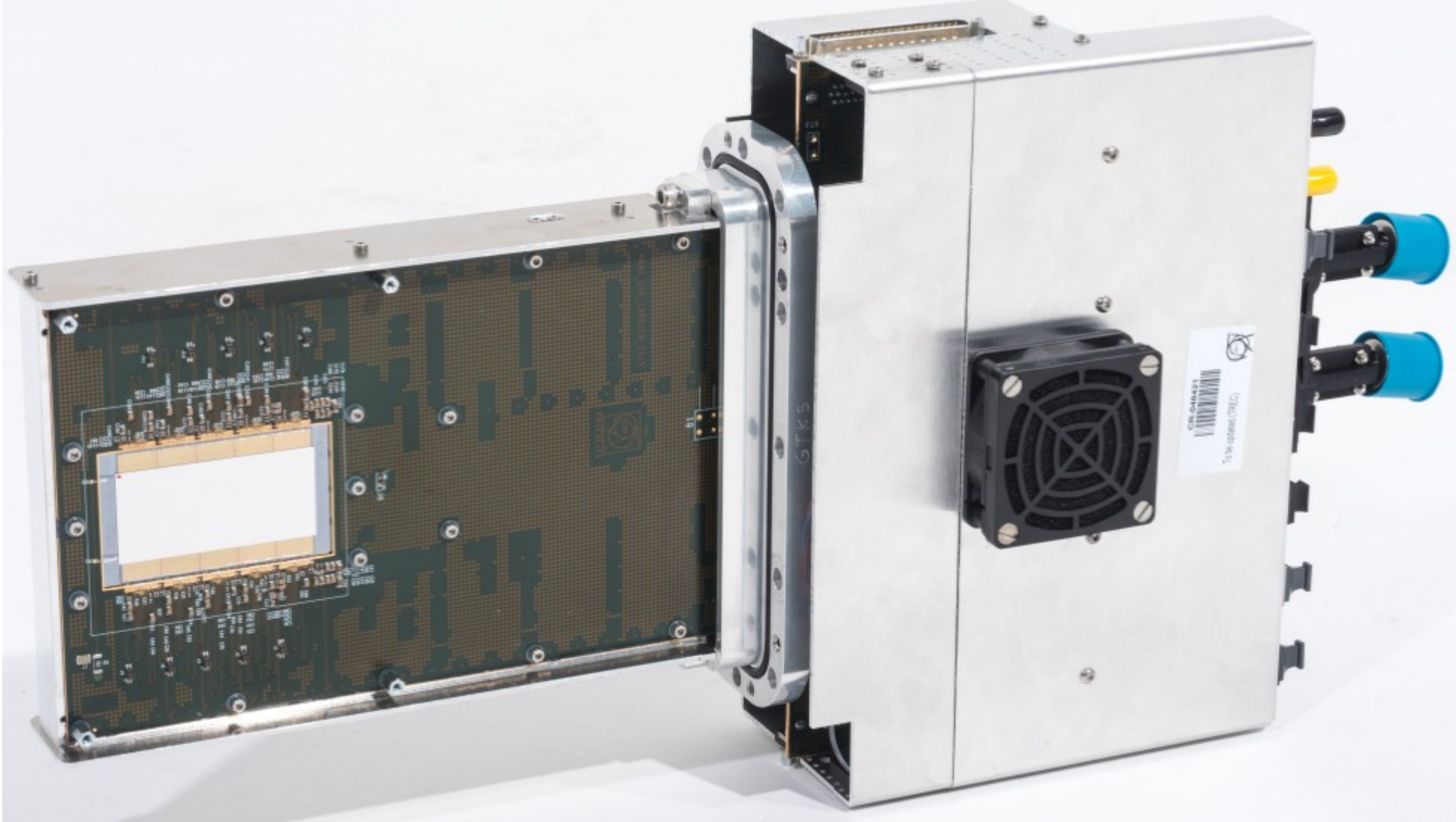


cooling

plate side

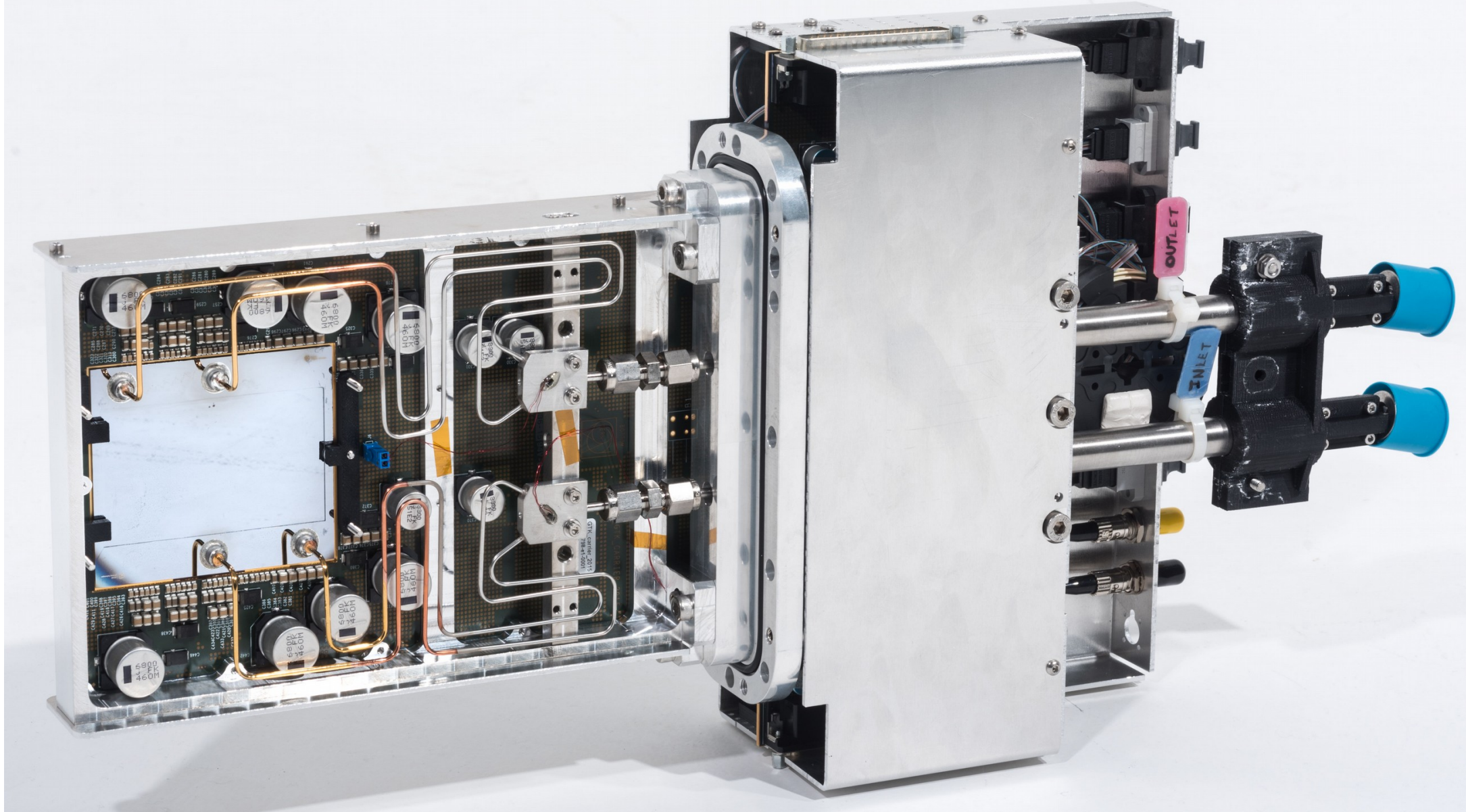


First GTK station installed in 2014

Three stations commissioned and integrated in the NA62 data taking since 2016

The measured GTK time-stamp resolution:

- 132.0 ps for GTK1

- 127.1 ps for GTK2

- 129.2 ps for GTK3 


\section{Performance}

Average integrated fluence of the three GTK stations in 2016-2017

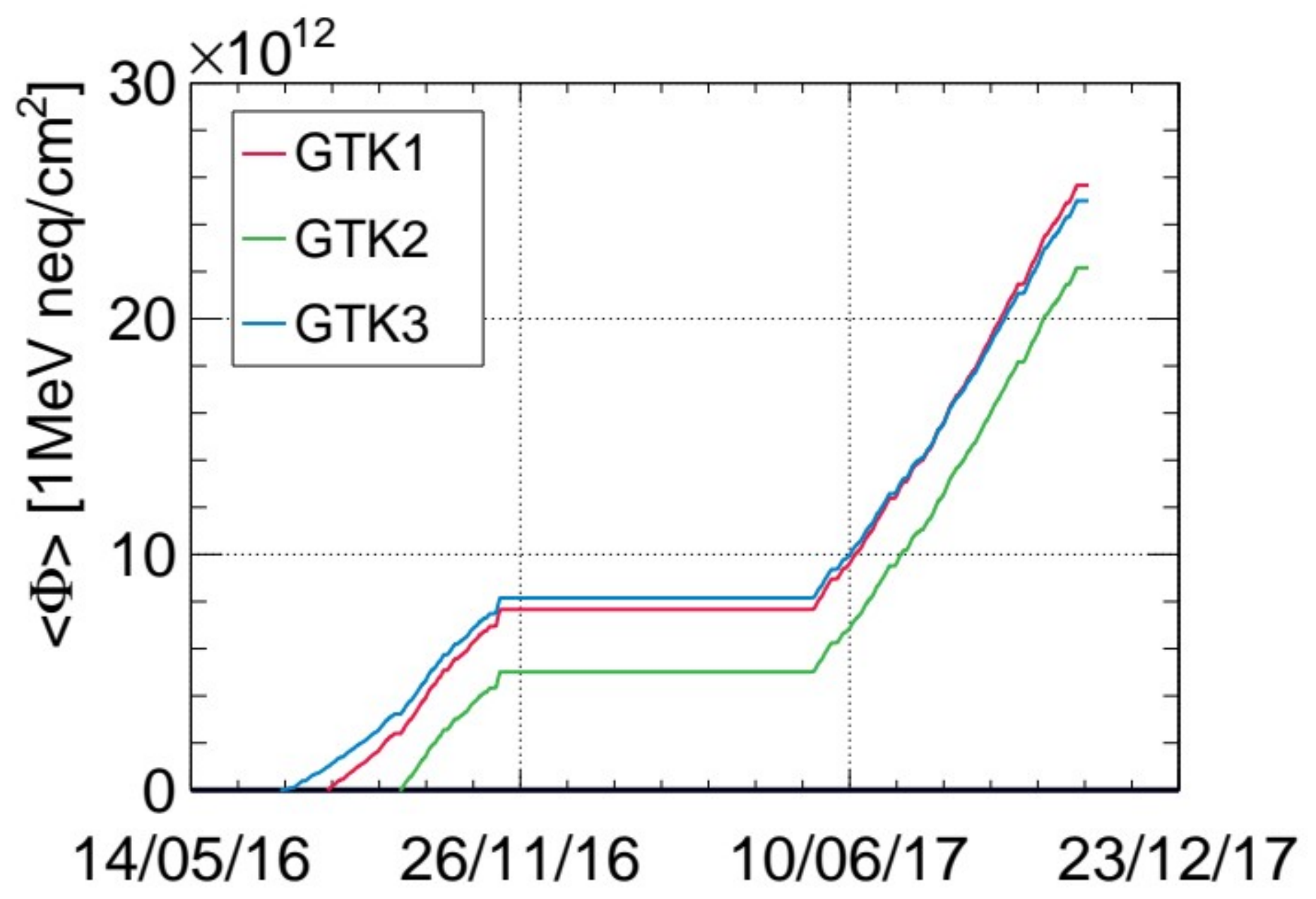




\section{Performance}

Degradation of the three GTK stations in 2016-2017

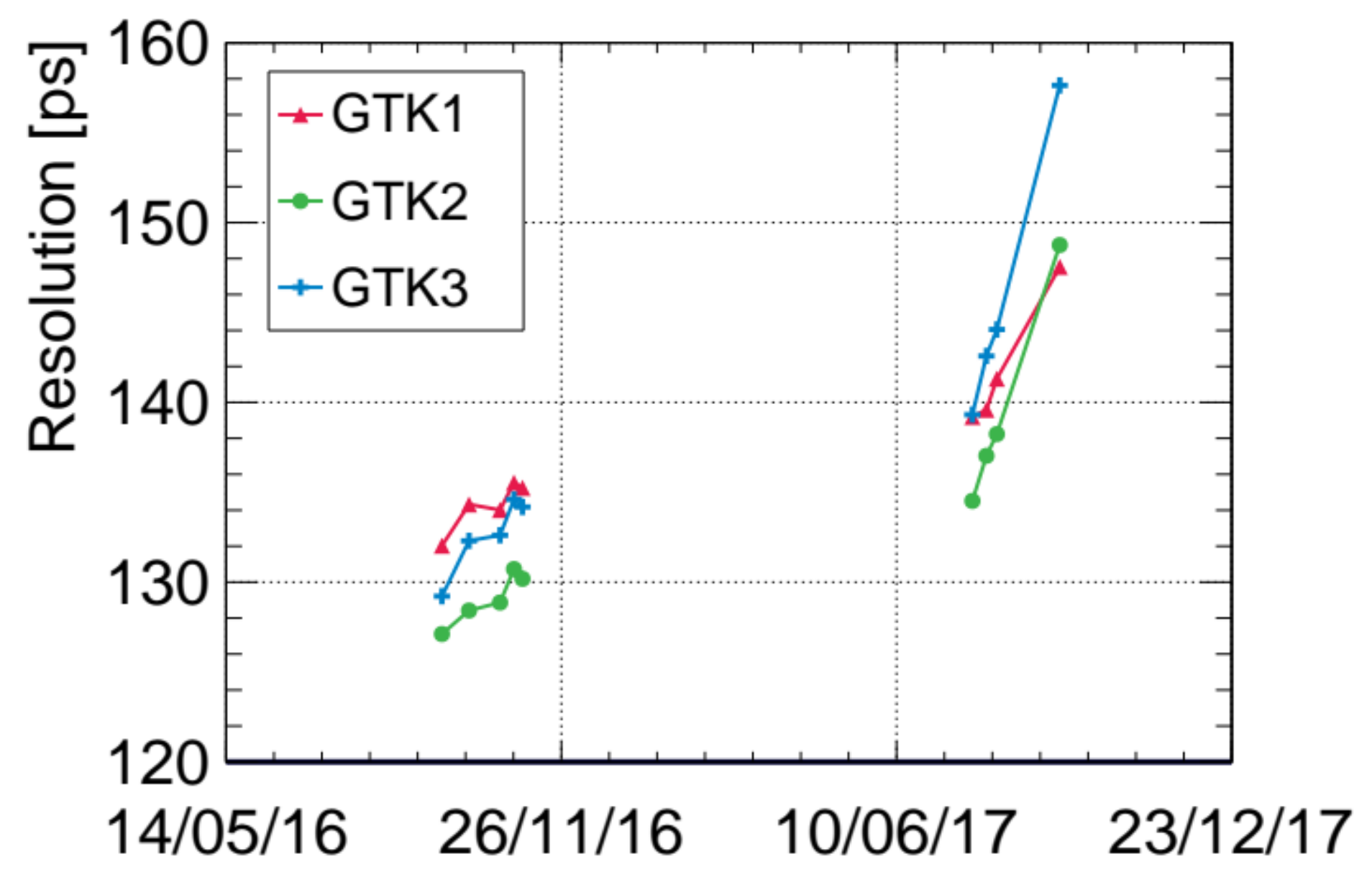




\section{Performance}

Degradation of the three GTK stations in 2016-2017

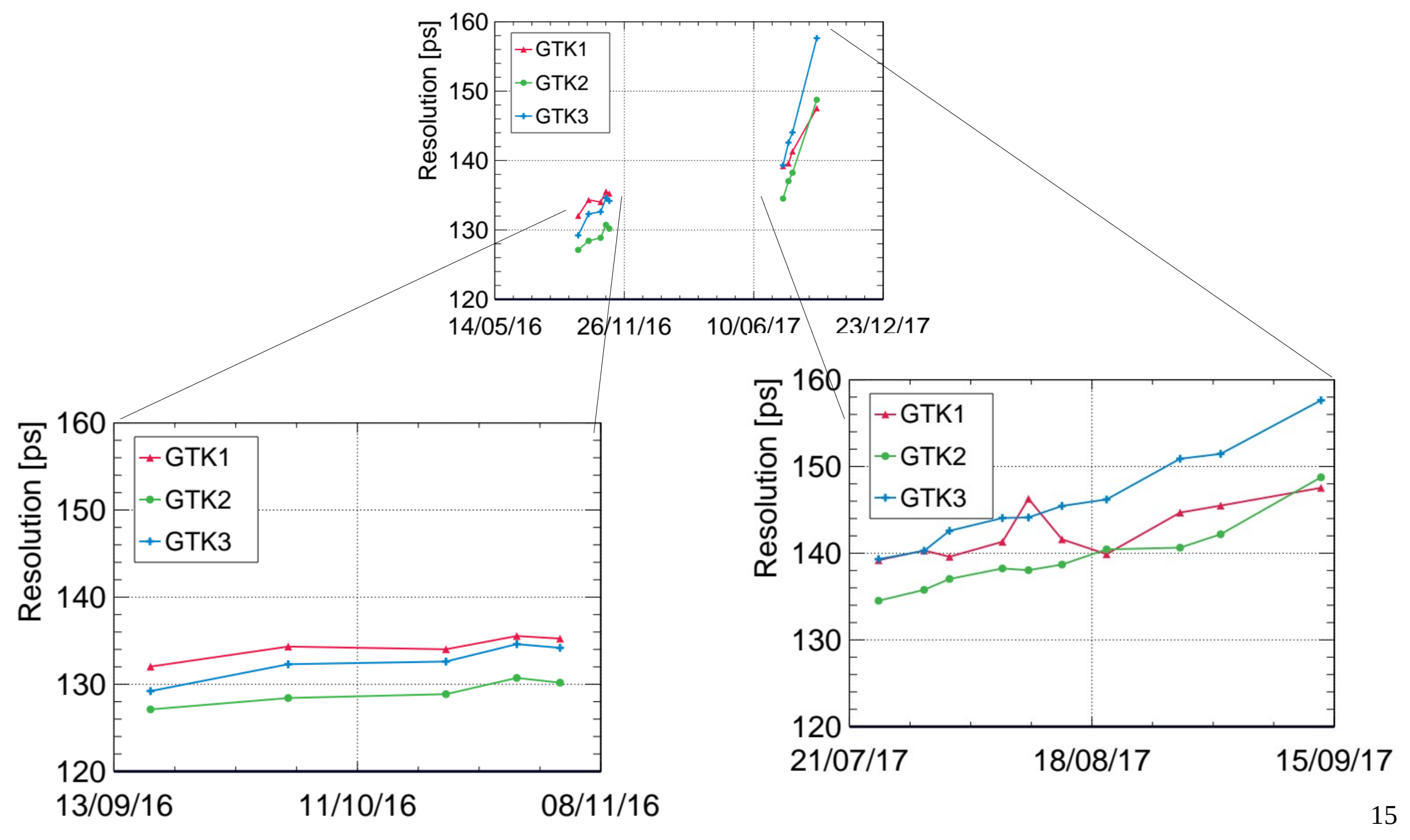




\section{NA62 data}

- the analysis of the data collected by NA62 in 2017 and 2018 is ongoing;

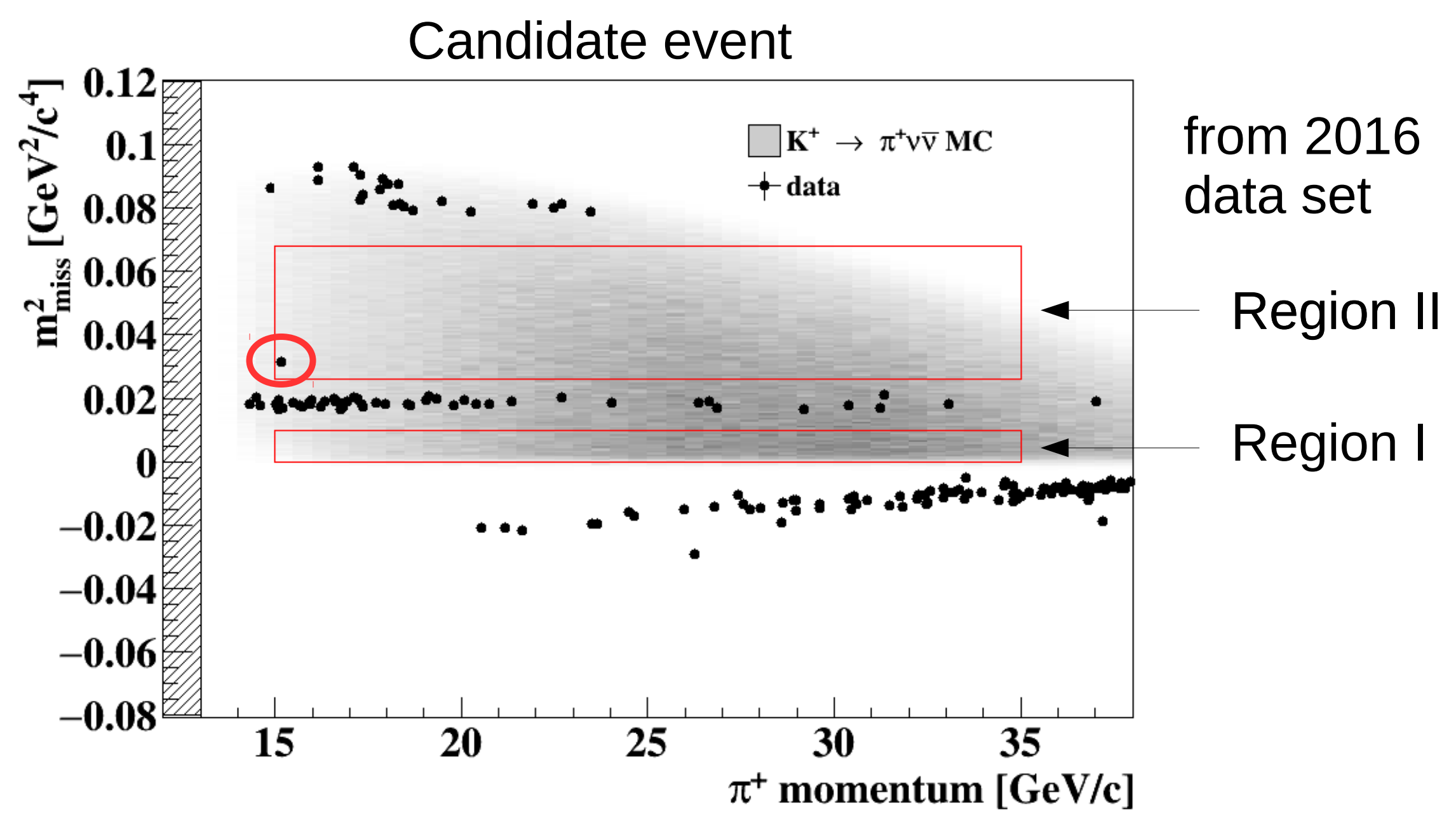


The first full NA62 GTK station has been installed in 2014

The three GTK stations have been integrated in the NA62 data taking in 2016

The GTK detector have been operating successfully since then until the end of the 2018 physics run. 